\title{
Pengaruh Kompensasi Terhadap Kinerja Karyawan Pada PT. Primacipta Graha Sentosa Di Jakarta
}

\author{
${ }^{1}$ Asep Sulaeman, ${ }^{2}$ N. Lilis Suryani, ${ }^{3}$ Lili Sularmi, ${ }^{4}$ Muhammad Guruh, \\ Universitas Pamulang \\ Email : $\underline{2}$ dosen00437@unpam.ac.id
}

(Diterima: Okt 2020; Direvisi: Nov 2020; Dipublikasikan: Jan 2021)

\begin{abstract}
ABSTRAK
Penelitian ini bertujuan untuk mengetahui pengaruh kompensasi terhadap kinerja karyawan pada PT. Primacipta Graha Sentosa di Jakarta. Metode yang digunakan adalah explanatory research dengan sampel sebanyak 61 responden. Teknik analisis menggunakan analisis statistik dengan pengujian regresi, korelasi, determinasi dan uji hipotesis. Hasil penelitian ini variabel kompensasi diperoleh nilai rata-rata skor sebesar 3,710 dengan kriteria baik. Variabel kinerja karyawan diperoleh nilai rata-rata skor sebesar 3,838 dengan kriteria baik. Kompensasi berpengaruh positif dan signifikan terhadap kinerja karyawan dengan nilai persamaan regresi $\mathrm{Y}=15,490+0,617 \mathrm{X}$, dan nilai koefisien korelasi 0,729 atau memiliki tingkat hubungan yang kuat dengan nilai determinasi $53,1 \%$. Uji hipotesis diperoleh signifikansi $0,000<0,05$.
\end{abstract}

Kata Kunci: Kompensasi, Kinerja Karyawan 


\section{PENDAHULUAN}

Semakin pesatnya kemajuan teknologi dunia yang saat ini maka semakin ketat juga persaingan bisnis antar organisasi. Berbagai tantangan yang dihadapi oleh perusahaanperusahaan dalam memasuki era global adalah adanya persaingan bisnis yang berupaya agar masingmasing tetap mampu bersaing dengan kompetitif.

Organisasi dan karyawan merupakan suatu kesatuan yang tak terpisahkan, yang terdiri dari berbagai individu yang memiliki latar belakang kompetensi yang berbeda-beda dan saling bekerja sama satu dengan yang lainnya. Dalam sebuah organisasi, setiap individu didalamnya selalu berusaha mewujudkan tujuan bersama dengan memanfaatkan seluruh sumber daya yang ada. Keberadaan sumber daya manusia yang handal memiliki peran yang lebih strategis dibandingkan sumber daya yang lain.

Suatu organisasi perlu di dukung oleh karyawan yang berkualitas dan profesional. Agar pegawai dapat mempunyai prestasi kerja yang baik, organisasi sangat perlu memperhatikan kompensasi yang diberikan kepada karyawan. Sadar akan pentingnya sumber daya manusia bagi kelangsungan hidup dan kemajuan suatu perusahaan, maka suatu perusahaan harus memberikan perhatian khusus pada faktor produksi ini dan sudah sewajarnya pemilik perusahaan memandang sumber daya manusia lebih dari sekedar aset perusahaan dan menjadikan mitra dalam berusaha. Perusahaan harus dapat bersikap adil atas apa yang telah diberikan oleh sumber daya manusia kepada perusahaan, karena setiap karyawan berhak mendapatkan penghargaan dan perlakuan yang adil dari pimpinannya sebagai timbal balik atas jasa yang diberikannya, sehingga dapat mendorong para karyawan untuk lebih termotivasi dalam menjalankan kewajibannya sebagai seorang pekerja. Hubungan kerja yang saling menguntungkan antara perusahaan dan karyawan sangat diperlukan dalam rangka mendorong semangat kerja karyawan. Karyawan memberikan hasil kerja yang baik untuk kemajuan perusahaan, sedangkan perusahaan memberikan kompensasi yang sesuai atas hasil kerja yang telah diberikan karyawan terhadap perusahaan.

Di dalam organisasi pimpinan harus dapat membina hubungan baik dengan pegawai, dengan cara memberikan insentif, gaji, honor, lembur, bonus dan tunjangantunjangan kesejahteraan para pegawai. Karena pada hakekatnya tenaga kerja akan lebih produktif apabila tenaga kerja tersebut menerima gaji dan honor yang seimbang dengan pekerjaan yang telah mereka kerjakan. Namun tunjangan-tunjangan tersebut tidak diberikan organisasi secara cumacuma. Para pegawai harus mampu menunjukkan prestasi yang dimilikinya selama ia bekerja di organisasi tersebut. Gaji, honor, dan insentif tidak saja sekedar cara untuk memuaskan kebutuhan fisik, melainkan juga merupakan pengakuan dan rasa mencapai sesuatu. Gaji dan honor merupakan salah satu alat motivasi untuk bekerja lebih keras dan berdampak dalam mengurangi pergantian pegawai.

Kompensasi merupakan segala sesuatu yang di terima para karyawan 
sebagai balas jasa untuk pekerjaan mereka. Maksud dari tujuan pemberian kompensasi ini yaitu untuk membantu karyawan memenuhi kebutuhan di luar kebutuhan rasa adil, serta meningkatkan motivasi kerja karyawan dalam menyelesaikan tugas-tugas yang menjadi tanggung jawabnya. Menurut Henry Simamora (2014:442) kompensasi adalah semua bentuk kembalian finansial, jasa-jasa terwujud dan tunjangan yang di peroleh karyawan sebagai bagian dari hubungan kekaryawanan. Sedangkan menurut Hasibuan (2014:118) Kompensasi adalah semua pendapatan yang berbentuk uang, barang langsung atau tidak langsung yang diterima karyawan sebagai imbalan atas jasa yang diberikan kepada perusahaan.

PT. Primacipta Graha Sentosa merupakan salah satu perusahaan yang bergerak dibidang pembangunan ruko atau perumahan yang selama ini konsentrasi bisnisnya menggarap pada pembangunan rumah dengan segmen pasar yang memiliki penghasilan menengah ke bawah.

Berdasarkan data survey dilapangan perusahaan memiliki kendala yaitu semakin menurunnya target penyelesaian pekerjaan pembangunan rumah. Hal ini disinyalir sebagai akibat pemberian kompensasi yang belum sepenuhnya dijalankan secara baik oleh perusahaan.

Dengan kompensasi yang diterima maka karyawan akan termotivasi untuk bekerja dengan sebaik-baiknya dan penuh tanggung jawab sehingga prestasi kerja meningkat. Semakin meningkatnya kinerja karyawan akan semakin menguntungkan bagi karyawan dan perusahaan sehingga dapat bersaing. Dengan pemberian kompensasi yang sesuai dengan peraturan yang berlaku bisa jadi mampu meningkatkan semangat karyawan dalam menjalankan tugas dan kewajibannya.

Kinerja dapat mempengaruhi berlangsungnya kegiatan suatu organisasi. Semakin baik kinerja yang ditunjukkan oleh para karyawan akan sangat membantu dalam perkembangan organisasi tersebut. Menurut Mangkunegara (2013:67) kinerja adalah hasil kerja secara kualitas dan kuantitas yang di capai oleh seorang pegawai dalam melaksanakan tugasnya sesuai dengan tanggung jawab yang diberikan kepadanya. Salah satu cara untuk memotivasi mereka guna dapat meningkatkan kinerja karyawan adalah dengan cara memberikan kompensasi kepada mereka. Hal ini diharapkan akan tercipta pola hubungan yang baik antara karyawan dengan perusahaan dimana karyawan akan berfikir tempat mereka bekerja dapat memahami serta damemenuhi kebutuhan hidup yang menjadi pemicu mengapa mereka bekerja.

Berdasarkan uraian yang telah dijelaskan diatas, penulis tertarik untuk melakukan penelitian yang lebih mendalam dengan judul "Pengaruh Kompensasi Terhadap Kinerja Karyawan Pada PT. Primacipta Graha Sentosa di Jakarta“".

\section{TINJAUAN PUSTAKA}

\section{Kompensasi}

Yang di maksud dengan kompensasi dalam penelitian ini adalah balas jasa yang diberikan perusahaan terhadap karyawan baik yang berbentuk uang atau barang, langsung maupun tidak 
langsung. Menurut Hendry Simamora (2014:442) kompensasi adalah semua bentuk kembalian finansial, jasa-jasa terwujud dan tunjangan yang di peroleh karyawan sebagai bagian dari hubungan kekaryawan.

\section{Kinerja Karyawan}

Yang di maksud dengan kinerja pada penelitian ini adalah hasil kerja secara kualitas dan kuantitas yang di capai oleh seorang karyawan dalam melaksanakan tugasnya sesuai dengan tanggung jawab yang diberikan kepadanya. Menurut Mangkunegara (2013:67) kineja adalah hasil kerja secara kulitas dan kuantitas yang di capai oleh seorang pegawai dalam melaksanakan tugasnya sesuai dengan tangung jawab yang diberikan kepadanya.

\section{METODE PENELITIAN}

\section{Populasi}

Populasi dalam penelitian ini berjumlah 61 responden PT.
Primacipta Graha Sentosa di Jakarta

\section{Sampel}

Teknik pengambilan sampling dalam penelitian ini adalah sampel jenuh, dimana semua anggota populasi dijadikan sebagai sampel. Dengan demikian sampel dalam penelitian ini sampel yang digunakan berjumlah 61 responden.

\section{Metode Analisis Data}

Dalam menganalisis data digunakan uji validitas, uji reliabilitas, analisis regresi linier sederhana, analisis koefisien korelasi, analisis koefisien determinasi dan pengujian hipotesis.

\section{HASIL PENELITIAN \\ 1. Analisis Deskriptif}

Pada pengujian ini digunakan untuk mengetahui skor minimum dan maksimum skor tertinggi, ratting score dan standar deviasi dari masing-masing variabel. Adapun hasilnya sebagai berikut:

Tabel 1. Hasil Analisis Descriptive Statistics

\section{Descriptive Statistics}

\begin{tabular}{lr|r|r|r|r} 
& N & Minimum & Maximum & Mean & \multicolumn{1}{c}{ Std. Deviation } \\
\hline Kompensasi (X) & 61 & 29 & 47 & 37.10 & 4.222 \\
\hline Kinerja Karyawan (Y) & 61 & 31 & 47 & 38.38 & 3.574 \\
\hline Valid N (listwise) & 61 & & & & \\
\hline
\end{tabular}

Kompensasi diperoleh varians minimum sebesar 29 dan varians maximum 47 dengan ratting score sebesar 3,710 dengan standar deviasi 4,222. Skor ini termasuk pada rentang sakala 3,40 - 4,19 dengan kriteria baik atau setuju.

Kinerja karyawan diperoleh varians minimum sebesar 31 dan varians maximum 47 dengan ratting score sebesar 3,838 dengan standar deviasi 3,574. Skor ini termasuk pada rentang sakala 3,40 - 4,19 dengan kriteria baik atau setuju.

2. Analisis Verifikatif.

Pada analisis ini dimaksudkan untuk mengetahui pengaruh variabel independen terhadap variabel dependen. 
Adapun hasil pengujian sebagai berikut:

a. Analisis Regresi Linier Sederhana

Uji regresi ini perubahan variabel dependen jika variabel independen mengalami perubahan. Adapun hasil pengujiannya sebagai berikut:

dimaksudkan untuk mengetahui

Tabel 2. Hasil Pengujian Regresi Linier Sederhana

Coefficients $^{\text {a }}$

\section{Unstandardized Standardized}

Coefficients Coefficients

\begin{tabular}{lr|r|r|r|r} 
Model & \multicolumn{1}{c}{ B } & Std. Error & Beta & \multicolumn{1}{c}{ t } & \multicolumn{1}{c}{ Sig. } \\
\hline 1 (Constant) & 15.490 & 2.817 & & 5.498 & .000 \\
\hline Kompensasi $(\mathrm{X})$ & .617 & .075 & .729 & 8.175 & .000 \\
\hline
\end{tabular}

Berdasarkan hasil pengujian pada tabel di atas, diperoleh persamaan regresi $\mathrm{Y}$ $=15,490+0,617 X$. Dari persamaan tersebut dijelaskan sebagai berikut:

1) Konstanta sebesar 15,490 diartikan jika kompensasi tidak ada, maka telah terdapat nilai kinerja karyawan sebesar 15,490 point.

2) Koefisien regresi kompensasi sebesar 0,617, angka ini positif artinya setiap ada peningkatan kompensasi sebesar 0,617 point maka kinerja karyawan juga akan mengalami peningkatan sebesar 0,617 point.

b. Analisis Koefisien Korelasi

Analisis koefisien korelasi dimaksudkan untuk mengetahui tingkat kekuatan hubungan dari variabel independen terhadap variabel dependen. Adapun hasil pengujian sebagai berikut:

Tabel 3. Hasil Pengujian Koefisien Korelasi Kompensasi Terhadap Kinerja

\section{Karyawan}

Correlations $^{\mathrm{b}}$

\begin{tabular}{llr|r} 
& & $\begin{array}{c}\text { Kompensasi } \\
(\mathrm{X} 1)\end{array}$ & $\begin{array}{r}\text { Kinerja Karyawan } \\
(\mathrm{Y})\end{array}$ \\
\hline Kompensasi (X) & Pearson Correlation & 1 & $.729^{* * *}$ \\
\cline { 2 - 4 } & Sig. (2-tailed) & & .000 \\
\hline Kinerja Karyawan (Y) & Pearson Correlation & $.729^{* *}$ & 1 \\
\cline { 2 - 4 } & Sig. (2-tailed) & .000 & \\
\hline
\end{tabular}

Berdasarkan
pengujian diperoleh nasil
korelasi sebesar 0,729 artinya
kompensasi memiliki hubungan
yang kuat terhadap kinerja
karyawan.

Berdasarkan hasil pengujian diperoleh nilai korelasi sebesar 0,729 artinya kompensasi memiliki hubungan karyawan. c. Analisis Koefisien Determinasi Analisis koefisien determinasi dimaksudkan untuk mengetahui besarnya persentase pengaruh dari variabel independen terhadap variabel dependen. Adapun hasil pengujian sebagai berikut: 
Tabel 4. Hasil Pengujian Koefisien Determinasi Kompensasi Terhadap Kinerja Karyawan

Model Summary

\begin{tabular}{lr|r|r|rr} 
Model & R & \multicolumn{2}{c|}{$\begin{array}{c}\text { Adjusted R } \\
\text { Rquare }\end{array}$} & \multicolumn{2}{c}{$\begin{array}{c}\text { Std. Error of the } \\
\text { Estimate }\end{array}$} \\
\hline 1 & $.729^{\mathrm{a}}$ & .531 & .523 & 2.468
\end{tabular}

a. Predictors: (Constant), Kompensasi (X

Berdasarkan hasil

pengujian diperoleh nilai determinasi sebesar 0,531 artinya kompensasi memiliki kontribusi pengaruh sebesar $53,1 \%$ terhadap kinerja karyawan, sedangkan sisanya sebesar 46,9\% dipengaruhi oleh faktor lain yang tidak dilakukan penelitian.

\section{Tabel 5. Hasil Uji Hipotesis Ko}

\begin{tabular}{|c|c|c|c|c|c|}
\hline \multirow[b]{3}{*}{ Model } & \multicolumn{2}{|c|}{ Coefficients ${ }^{\mathrm{a}}$} & \multirow[b]{2}{*}{$\begin{array}{l}\text { Standardized } \\
\text { Coefficients }\end{array}$} & \multirow[b]{3}{*}{$\mathrm{t}$} & \multirow[b]{3}{*}{ Sig. } \\
\hline & $\begin{array}{r}\text { Unstan } \\
\text { Coef }\end{array}$ & $\begin{array}{l}\text { dardized } \\
\text { icients }\end{array}$ & & & \\
\hline & B & Std. Error & Beta & & \\
\hline $\begin{array}{ll}1 & \text { (Constant) }\end{array}$ & 15.490 & 2.817 & & 5.498 & .000 \\
\hline Kompensasi (X) & .617 & .075 & .729 & 8.175 & .000 \\
\hline
\end{tabular}

d. Uji Hipotesis

Pengujian hipotesis dengan uji $\mathrm{t}$ digunakan untuk mengetahui hipotesis mana yang diterima.

Rumusan hipotesis: Terdapat pengaruh yang signifikan antara kompensasi terhadap kinerja karyawan.

a. Dependent Variable: Kinerja Karyawan (Y)

Berdasarkan hasil pengujian pada tabel di atas, diperoleh nilai $\mathrm{t}$ hitung $>\mathrm{t}$ tabel atau $(8,175>2,001)$, dengan demikian hipotesis yang diajukan bahwa terdapat pengaruh yang signifikan atara kompensasi terhadap kinerja karyawan diterima.

\section{PEMBAHASAN}

HASIL

\section{PENELITIAN}

1. Kondisi Jawaban Responden Variabel Kompensasi

Berdasarkan jawaban responden, variabel kompensasi diperoleh ratting score sebesar 3,710 berada di rentang skala 3,40-4,19 dengan kriteria baik atau setuju

2. Kondisi Jawaban Responden Variabel Kinerja Karyawan
Berdasarkan jawaban responden, variabel kinerja karyawan diperoleh ratting score sebesar 3,838 berada di rentang skala 3,40 - 4,19 dengan kriteria baik atau setuju.

3. Pengaruh Terhadap Kinerja Karyawan

Kompensasi berpengaruh signifikan terhadap kinerja karyawan dengan persamaan regresi $Y=15,490+0,617 X$, nilai korelasi sebesar 0,729 atau memiliki hubungan yang kuat dengan kontribusi pengaruh sebesar 53,1\%. Pengujian hipotesis diperoleh nilai t hitung > $\mathrm{t}$ tabel atau $(8,175>2,001)$. Dengan demikian hipotesis yang diajukan bahwa terdapat berpengaruh signifikan antara 
kompensasi terhadap kinerja karyawan diterima.

\section{KESIMPULAN DAN SARAN}

\section{A. Kesimpulan}

1. Variabel kompensasi diperoleh ratting score sebesar 3,710 berada di rentang skala 3,40 4,19 dengan kriteria baik atau setuju.

2. Variabel kinerja karyawan diperoleh ratting score sebesar 3,838 berada di rentang skala 3,40 - 4,19 dengan kriteria baik atau setuju.

3. Kompensasi berpengaruh signifikan terhadap kinerja karyawan dengan persamaan regresi $\mathrm{Y}=15,490+0,617 \mathrm{X}$, nilai korelasi sebesar 0,729 atau kuat dan kontribusi pengaruh sebesar $53,1 \%$ sedangkan sisanya sebesar 46,9\% dipengaruhi faktor lain. Uji hipotesis diperoleh nilai t hitung $>$ t tabel atau $(8,175>2,001)$.

\section{B. Saran}

1. Perusahaan harus mampu melakukan perbaikan terkait dengan pengupahan dan standar penggajian yang mengacu pada peraturan pemerintah

2. Kinerja perusahaan dapat ditingkatkan dengan memberdayakan karyawan dengan menegakkan peraturan yang baik dan pemberian motivasi yang lebih inten lagi.

\section{DAFTAR PUSTAKA}

Akbar, I. R., Prasetiyani, D., \& Nariah, N. (2020). Pengaruh Motivasi Terhadap Kinerja Karyawan Pada Pt. Unggul
Abadi Di Jakarta. Jurnal Ekonomi Efektif, 3(1).

Algifari. (2015). Analisis Regresi untuk Bisnis dan Ekonomi. Yogyakarta: BPFE.

Arikunto, Suharsimi (2014). Prosedur Penelitian Suatu Pendekatan Praktek. Jakarta: Rineka Cipta.

Bangun, Wilson. (2012). Manajemen Sumber Daya Manusia. Jakarta: Erlangga

Bejo Siswanto (2013) Manajemen Tenaga Kerja Rancangan dalam Pendayagunaan dan Pengembangan Unsur Tenaga Kerja, Bandung: Sinar Baru.

Dessler, G. (2006.) Manajemen Sumber Daya Manusia (Jilid II). Jakarta: Indeks.

Edi Sutrisno (2016). Manajemen Sumber Daya Manusia. Jakarta: Prenadamedia Group.

Effendy, A. A., Sunarsi, D., Kristianti, L. S., Irawati, L., \& Wahyitno, W. (2020). Effect Of Giving Reward and Motivation to Employee Productivity In PT. Sinar Kencana Jaya In Surabaya. HUMANIS (Humanities, Management and Science Proceedings), 1(1).

Effendy, A., \& Sunarsi, D. (2020). Persepsi Mahasiswa Terhadap Kemampuan Dalam Mendirikan UMKM Dan Efektivitas Promosi Melalui Online Di Kota Tangerang Selatan. Jurnal Ilmiah MEA (Manajemen, Ekonomi, \& Akuntansi), 4(3), 702-714. https://doi.org/10.31955/mea.v ol4.iss3.pp702-714

George Terry R \& Rue, Leslie W. Rue (2016) 
Manajemen, Jakarta Bumi Aksara.

Gerry Dessler (2016) Human Resources Management, Prenticehall, London: International Inc.

Handoko (2016) Manajemen Personalia dan Sumberdaya Manusia. Yogyakarta: BPFE.

Hasibuan, Malayu S.P. (2016). Manajemen Sumber Daya Manusia. Edisi Revisi. Jakarta: PT Bumi Aksara.

Imam Ghozali (2017). Aplikasi Analisis Multivariate Dengan Program SPSS. Edisi Kelima. Semarang: Badan Penerbit Undip.

Jasmani, J., \& Paeno, P. (2019). The Effect of Leadership and
Competence on Lecturer

Performance and Its Implications on Student Learning Motivation at Pamulang University. International Journal of Advances in Social and Economics, 1(4).

Jasmani, J., \& Sunarsi, D. (2020). The Influence of Product Mix, Promotion Mix and Brand Image on Consumer Purchasing Decisions of Sari Roti Products in South Tangerang. PINISI Discretion Review, 1(1), 165174.

Luthans Fred (2014) Organizational Behavior, New York: McGrawHill. 